\title{
FIELD TRIALS AGAINST GRASS GRUB INCLUDING SOME NEWER INSECTICIDES
}

\author{
P. G. Fenemore \\ Entomology Division, Department of Scientific and Industrial \\ Research, Nelson \\ Summary \\ Two field trials laid down against grass grub (Costelytra zealandica) \\ larvae in 1968 and observed for a further two seasons are de- \\ scribed. Fensulfothion at $2 \mathrm{lb}$ a.i./acre gave satisfactory results. \\ Some effect was produced by "Mocap", carbofuran and parathion. \\ All other materials (phoxim, GC-6506 and Bayer 68138) were in- \\ effective.
}

\section{TRIAL 1. GARDINER, BRIGHTWATER, NELSON}

\section{Treatment Details}

The insecticides used, formulations and rates of active ingredient per acre are listed in Table 1. Rates are expressed in terms of active ingredient per acre. Plots were $15 \times 15 \mathrm{ft}$ with 10 replications in randomized blocks.

Treatments were first applied on March 14, 1968, when rain had been forecast. Practically no rain fell, however, and it remained dry for a further three weeks (see rainfall records below). Because of this, it was decided to re-treat half the trial ( 5 of the 10 replications). This was done on April 18,1968, and $1 / 4$ in. of rain fell immediately following this treatment.

On the day following each date of treatment, twenty $1 / 8$ sq. ft cores were taken adjacent to the trial area and sectioned into layers of 0 to 1 , 1 to 2,2 to 3 , and 3 to 8 in. below the surface, and grubs in each layer recorded. The results were as follows:

$$
\begin{aligned}
& \begin{array}{l}
\text { Date } 0 \text { to } 1 \mathrm{in.} 1 \text { to } 2 \mathrm{in.} 2 \text { to } 3 \mathrm{in.} \quad 3 \text { to } 8 \mathrm{in.}
\end{array} \\
& \begin{array}{llllllll}
\text { March } 15 & \ldots . & \ldots . & \ldots . & 31 & 22 & 12 & 35
\end{array} \\
& \begin{array}{llllllll}
\text { April } 19 & \ldots . & \ldots . & \ldots . & 31 & 22 & 12 & \\
& & & & & &
\end{array}
\end{aligned}
$$

RESUlts

Results were assessed by sampling for numbers of grubs present in plots at various intervals after treatment during the season of application 1968, and in 1969 and 1970. The plots were also observed for pasture growth differences and, when these were apparent, were scored on a scale of 0 to 10 for density and height of growth by four observers working independently. Such pasture growth estimates were made on May 23, 1968, and April 10, 1969. 
Because of the double application on part of the trial, results are presented separately for each half of the trial in Table 1.

Weekly totals of rainfall recorded on the site for the five or six weeks following each application were as follows:

Week ending

1st treatment

March 14

March 20

March 27

April 3

April 10

April 17

2nd treatment

April 18

$\begin{array}{ll}\text { April 24 } & 0.670 \\ \text { May 1 } & 0.098 \\ \text { May } 8 & 0.779 \\ \text { May 15 } & 0.004 \\ \text { May 22 } & 1.879 \\ \text { May 29 } & 2.182 \\ \text { June 5 } & 0.917\end{array}$

TRIAL 2: INGLIS, MOTUEKA
Rainfall (in.)

0.020

0

0.102

4.229

0.269

0.670

0.098

0.004

2182

0.917

\section{Treatment Details}

The insecticides used, formulations and rates of active ingredient per acre are listed in Table 2, together with the results of sampling.

Plots were $15 \times 15 \mathrm{ft}$ with 8 replications in randomized blocks.

Treatments were applied on May 3, 1968. GC-6506 was applied as wettable powder in 2 gal water per plot by watering-can followed immediately by a further 20 gal water per plot to wash it into the surface layers of soil.

On the same day that treatments were applied, twenty $1 / 8 \mathrm{sq} . \mathrm{ft}$ cores were taken adjacent to the trial area and sectioned into depth layers as in Trial 1. The percentage of larvae at each depth from the surface were as follows:

$$
\% \text { at depth }
$$

$\begin{array}{llllll}\text { May } 5 & 59 & 28 & 4 & 9\end{array}$

Larvae were therefore somewhat closer to the surface than when treatments were made in Trial 1.

\section{Results}

Plugs of soil $11 / 4$ in. in diameter were taken three per plot to a depth of approximately $4 \mathrm{in}$. on two occasions following treatment - on May 10, 1968 (seven days after treatment), and on June 14, 1968 (six weeks after treatment). Each plug sample was cut into portions corresponding to 0 to 1 in., 1 to 2 in, 2 to 3 in. depth from the soil surface and samples from each plot of the same treatment were bulked. The samples were 


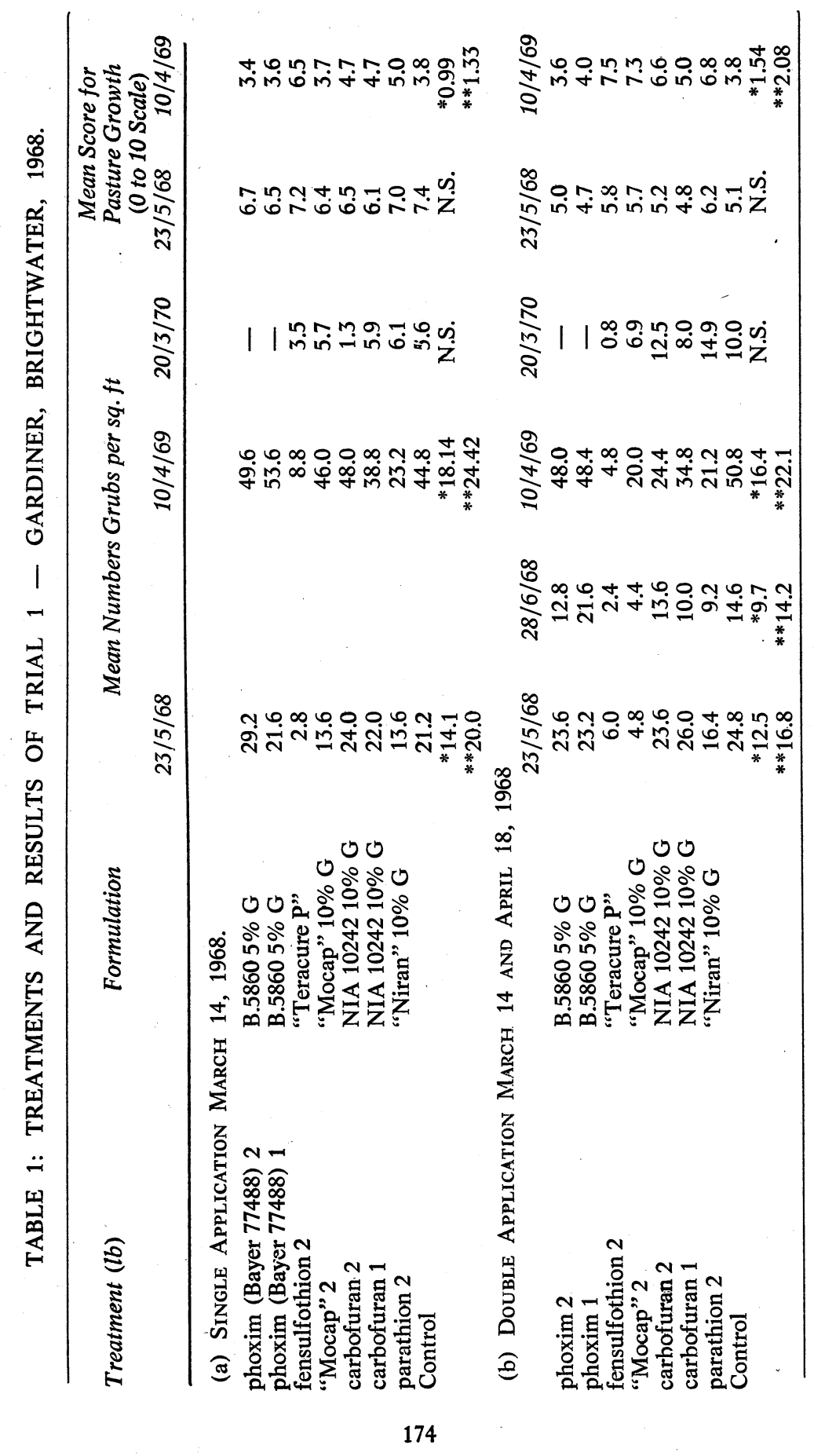




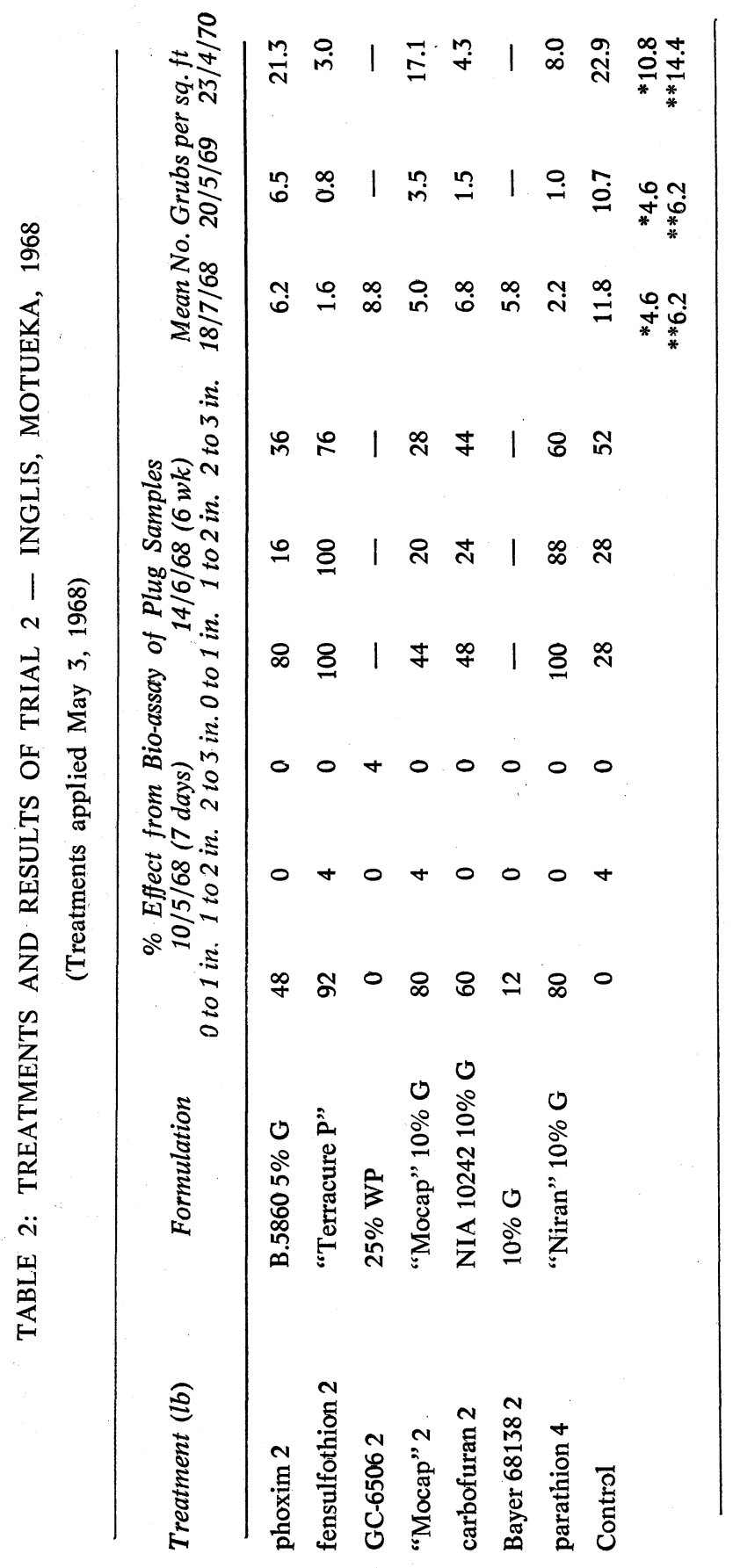

175 
returned to the laboratory, sieved and set up with freshly collected grubs (batches of 25) on the same day they were collected. The grubs were held in the soil samples for two weeks at $13^{\circ} \mathrm{C}$ then assessed for effect by ability to burrow into moist untreated soil. Results are presented in Table 2.

Plots were sampled for surviving grubs during the season of treatment and in the two following. Results are given in the table.

The trial area was observea at intervals after treatment for possible growth differences between plots, but no differences sufficient to justify assessment were observed.

\section{DISCUSSION}

The following are the major features from these two trials worthy of comment:

(1) Fensulfcthion (included as a standard of comparison) gave satisfactory results in each instance, even when application was followed by three weeks of warm, dry weather. An effective level of control was maintained for at least two seasons.

(2) "Mocap" was reasonably effective with a double application each at $2 \mathrm{lb}$ but not with a single application.

(3) Carbofuran was not effective in the season of application but did produce a significant effect in the second year in one case.

(4) Parathion produced little effect in Trial 1 even with two applications each of $2 \mathrm{lb}$. In Trial 2, however, a satisfactory result was achieved with $4 \mathrm{lb}$ and this effect persisted into the second season.

(5) The plug sampling technique followed by laboratory bioassay used in Trial 2 gave good correlation with the field results and may be useful in conjunction with a microplot treatment procedure prior to full-scale field trials with new materials. 